\title{
白金一ニオブ系状態図の研究
}

\section{木村啓造** 伊藤祥***}

Hirozo Kimura and Akira Ito: The Platinum-Niobium System. The binary system platinum-niobium has been investigated by $\mathrm{X}$-ray analysis, microscopic examination and liquidus temperature determination. The platinum phase $(\alpha)$ dissolves up to 36 at $\% \mathrm{Nb}$ and the lattice parameter of platinum increases from $3.916 \mathrm{kX}$ to $3.956 \mathrm{kX}$ with alloying of niobium. The melting point of $\alpha$-phase alloy rises with increasing of niobium content and 36 at $\% \mathrm{Nb}$ alloy shows the maximum rise $2000^{\circ} \mathrm{C}$. There are two intermetallic compounds, $\mathrm{PtNb}_{2}$ and $\mathrm{PtNb}_{3}$, in this system. $\mathrm{PtNb}_{2}$ is formed by a peritectic reaction of liquid+ $\mathrm{PtNb}_{3} \rightleftharpoons \mathrm{PtNb} b_{2}$ at about $1900^{\circ} \mathrm{C}$. $\mathrm{PtNb}_{2}$ has a tetragonal lattice, and forms an eutectic with $\alpha-$ phase of 36 at $\% \mathrm{Nb}$ at $1700^{\circ} \mathrm{C}$. The eutectic composition is 45 at $\% \mathrm{Nb}$. Thers is a peritectic reaction between $\mathrm{Nb}$ and $\mathrm{PtNb}_{3}$ as follows: liquid $+\mathrm{Nb} \rightleftharpoons \mathrm{PtNb}_{3}$ at about $2000^{\circ} \mathrm{C}$. $\mathrm{PtNb}_{3}$ has a $\beta-$ wolfram type cubic structure and its lattice parameter increases from 5.137 to $5.156 \mathrm{kX}$ with increasing of niobium. The solubility limit of platinum in niobium is less than 1 at $\% .25$ at $\% \mathrm{Nb}$ alloy (correspond to $\mathrm{Pt}_{3} \mathrm{Nb}$ ) has a random array of platinum and niobium atoms on facecentered cubic lattice at high temperature and shows a disordered structure. The formation of a superlattice takes place below a critical temperature, and its temperature is close to the solidus and is estimated as about $1800^{\circ} \mathrm{C}$.

(Received September 30, 1960)

\section{I. 緒言}

Pt 基として高融点金属（例兄ばW，Re，Ta， Nb，Mo など）を添加した白金合金はPt自体のるつ櫌れた酎食性を 军することなく，硬度や强度などを增し再結晶温度が高く なるので高級な装植材料やその特性を利用した特殊な用途 亿用いられている、Nbが金属材料として用いられるよう になつたのは最近のことであるため，Pt-Nb 系合金につ いては従来若干のX線結晶学的な研究が発表されている が，その諸性質などについては未知である。この報告では $\mathrm{Pt}-\mathrm{Nb} 2$ 元系の平衡状態医を明らかにした。

\section{II. 試料の作成おょび実験方法}

純度 99.99\%のPt板と Fansteel 社製純度 $99.6 \%$ のb 粉末を用いた. $\mathrm{Nb}$ の主な不純物は $\mathrm{O}_{2} 0.1 \%, \mathrm{~N}_{2} 0.05 \%$, C $0.02 \%$, Fe $0.02 \%$, Ti $0.02 \%$, Ta $0.08 \%$, Zr $0.02 \%$, Ni $0.01 \%, W 0.01 \%$, 粒度 300 mesh であった.

この報告では合金の組成はすべて at \% で表示すること とし，35 種類についてそれぞれ計算量の原料を化学天秤で 正しく科り，外側をPt簿で包むようにして型に入れ，約 $3 \mathrm{t} / \mathrm{cm}^{3}$ の压力で加圧成形してブリケットを作つた．愹 解は $W$ チップおよび水冷 $\mathrm{Cu}$ るつぼを持つ非消耗式の実 験用小型アーク炉を用い，Ar 気流中で綝返し 5 回熔解し た. 試料の総量は 5 10g でこれらはすべて熔解の前媵の 重量差を測つて熔解損失の状況を検討したが，通常この損 失量は $20 \mathrm{mg}$ 以下で極めてわずかであつた。熔解したボタ ン試料の断面について顕微鏡括よび硬度分布測定によつて 偏析の有無を調べたが，組成は均一で势つた。

\footnotetext{
*** 科学技術朾金属材料技術研究所

*** 石福金属藇業株式会社

*1960年 4 月本会東京大会以発表
}

熔解中の不純物混入を調べるため，分光分析を行つたが フーク熔解に際し炣の材質による污染が考方られる元素，

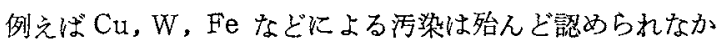
つた。これらの検討により予定組成の試料が得られたるの として取报い，化学分析は行わなからた。

試料の熱処理山空気酸化やその他の不純分に上る污染を 防ぐため，Pt 側の合金は $0.01 \mathrm{~mm}$ P $\mathrm{t}$ 䇴および 0.015 $\mathrm{mm}$ の $\mathrm{Nb}$ 管で包み， $50 \% \mathrm{Nb}$ 以上の合金は直接 $\mathrm{Nb}$ 箔で 包んで保護した上石英管内に $\mathrm{Ar}$ と共に封入して行った。

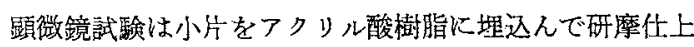
け゚をした後，尖端をPtで作つたピンせットで摤み，黑鉛 電極と組み合せて交流電解腐食を行つた，腐食はPt 側の 試料対しては 10\% $\mathrm{HCl}$ に NaCl を飽和させた溶液を用 い15 20Vの交流(50の)で 1〜3 分間の条件で行つた. $\mathrm{Nb}$ の配合量が多くなれば腐食され易くなるので電长を低くす るかまたは府食液の酸濃度を減じて適当な腐食面が得られ るように調節を行つた．Nb 側の合金では 10\% HF-10\% $\mathrm{HCl}$ 溶液を用い電解腐食恃行斿なかつたが，Pt量の增加 に伴つて酸洪度を高めるかまたは10１5V の交流を併好 用いた.

$\mathrm{X}$ 楾分析は $\mathrm{CuK}_{\alpha}(\mathrm{Ni}$ フィルター使用)を用い, $90 \mathrm{~mm}$ のデバイカメラを用いた、融点の測定は $10^{-4} \mathrm{mmHg}$ の真 架中でMo 発熱体に上り加熱し試料が愹融する状況を観測 し，その時の温度を光高温計により測定した。

\section{III. 実験結果および考察}

\section{1. $\alpha$ 相 (Pt 相)について}

Pt の結晶構造はf.c.c.で格子常数は $3.916 \mathrm{kX}$ であるが かなり多量の $\mathrm{Nb}$ を固溶する。背面反射法により $а$ 相の試 料の格子常数を測定してPtに対するNbの添加の影響を調 
べた結果をFig.1 に示す.Pt-Nb 系の鋳造組織はFig.2の

X線分析に示すように $40 \% \mathrm{Nb}$ をではf.c.c.構造をもち,

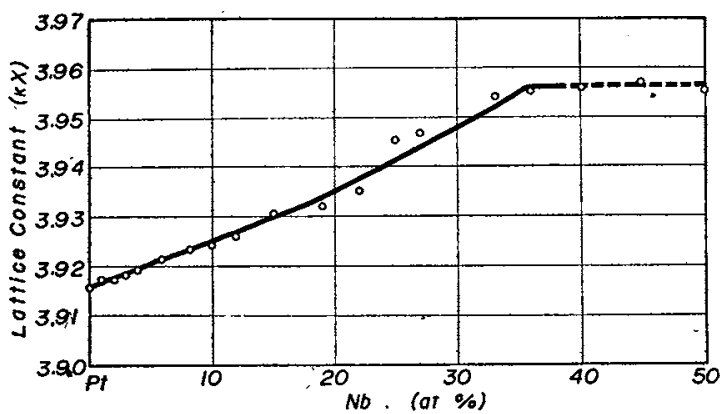

Fig. I Effect of niobium on the lattice parameter of $\alpha$-phase.

\begin{tabular}{|c|c|c|}
\hline $\begin{array}{l}\text { at \% of } \\
\text { Niobium }\end{array}$ & $\begin{array}{c}x \text {-Ray Powder Diffraction } \\
\text { Pattern of as Cost Alloy }\end{array}$ & $\begin{array}{l}\text { Microstructure } \\
\text { of as Cast Alloy }\end{array}$ \\
\hline 99.6 & 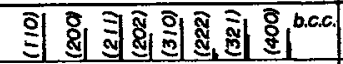 & Single (Nb) \\
\hline 97 & & $\begin{array}{c}\mathrm{Nb}+\mathrm{P}+\mathrm{Nb}_{3} \\
\text { (boundaries) }\end{array}$ \\
\hline 95 & 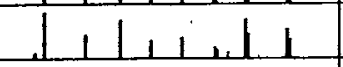 & $\begin{array}{c}\operatorname{Primary}_{+\mathrm{P}}+\mathrm{Nb}_{s} \\
\end{array}$ \\
\hline 90 & 山l & : \\
\hline 85 & $\|$ & - \\
\hline 80 & لـ & " \\
\hline 75 & $\|$ & Single $\left(\mathrm{P}+\mathrm{Nb}_{3}\right)$ \\
\hline 70 & ill & $\begin{array}{c}\text { Primary } P+N b_{3} \\
+P+N b_{2}\end{array}$ \\
\hline 66 & 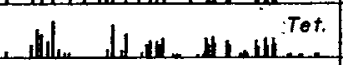 & 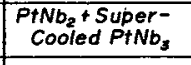 \\
\hline 64 & Ih. & $\mathrm{PtNb}_{2}$ (Poritectia) \\
\hline 60 & L. & $\begin{array}{c}\text { Primary } P+N b_{2} \\
\text { +Eutectic }\end{array}$ \\
\hline 55 & & $"$ \\
\hline 50 & & $"(P+N b)$ \\
\hline 45 & L. & \begin{tabular}{|l} 
Eutectic \\
$P+N b_{2}+\alpha$ \\
\end{tabular} \\
\hline 40 & 1 & $\begin{array}{c}\text { Primary } \alpha \\
\text { +Eutectic }\end{array}$ \\
\hline 36 & 1 & $\begin{array}{l}\text { Solubility Limit } \\
\text { of } \mathrm{Nb} \text { in } \alpha\end{array}$ \\
\hline 33 & $山 11$ & $\alpha$ \\
\hline 27 & $\mathrm{~L}_{1} \quad 1 / 1$ & $"$ \\
\hline 25 & lul 1 li & $\begin{array}{r}\text { Essentiolly } \alpha \\
\left(P t_{3} N b\right) \\
\end{array}$ \\
\hline 24 & Jul 1 h 11 & $\alpha$ \\
\hline 19 & U & $"$ \\
\hline 8 & 1 & Large Grained $\alpha$ \\
\hline Platinum & 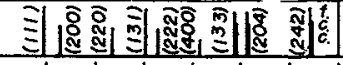 & $\alpha$ \\
\hline
\end{tabular}

Fig.2 X-ray diffraction patterns of platinumniobium alloys, as cast. (with $\mathrm{Cu} \mathrm{K}_{\alpha}$ radiation)

格子常数は Nbの含有量に汪任比例して大となり最大值は $3.95 \mathrm{kX}$ である。ただ後术するよ5に25\%( $\left.\mathrm{Pt}_{3} \mathrm{Nb}\right)$ を中 心とする組䄼範囲で規則格子变態があるので 22〜29\%の

籁围では融液より急冷したときf.c.c. 構造が観察される。 30〜 40\% の範围では再びf.c.c. 構造が 安定し, 熬処理に

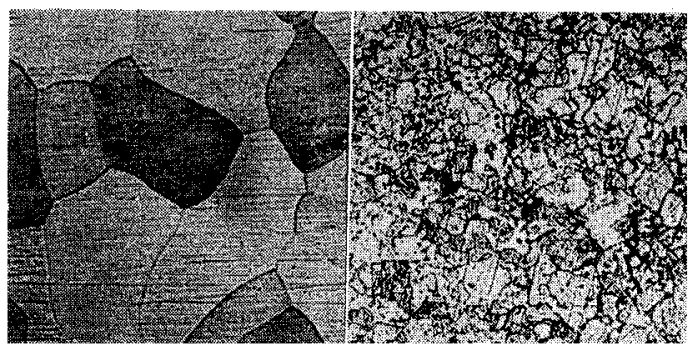

Photo.1 15 at \% alloy, Photo.2 36 at \% alloy, as as cast, Single phase cast, Upper solubility of $\alpha . \quad(\times 200)$ limit of $\alpha$ phase. $(\times 200)$

よつても殆んど差異がないが、デバイ輸のけが広くなるの で $\theta \fallingdotseq 72^{\circ}$ に得られる(242) からの $\mathrm{K}_{\alpha_{1}}$ と $\mathrm{K}_{\alpha_{2}}$ による干涉 楾の鐡別が困難であつた。

融点はPtの $1769^{\circ} よ り \mathrm{Nb}$ 添加量が增すに従つて高 くなり $36 \%$ で $2000^{\circ}$ の極大点を持ち，それ以上ではか党 つて低くなつている。これは後速するよ5に45\%の点に 共晶反応があるためである．顕徽鏡検查の結果もX線分析

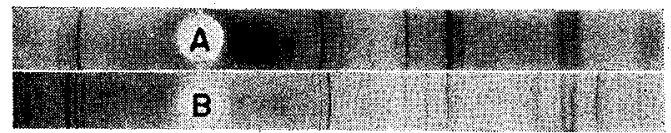

Photo.3 Powder diffraction patterns of 25 at\% alloy.

(A) Arc cast structure, Essentially disordered f.c.c arrengement of $\alpha$ phase.

(B) Annealed for $20 \mathrm{hrs}$ at $1300^{\circ}$, It shows the formation of super lattice of $\mathrm{Pt}_{3} \mathrm{Nb}$.

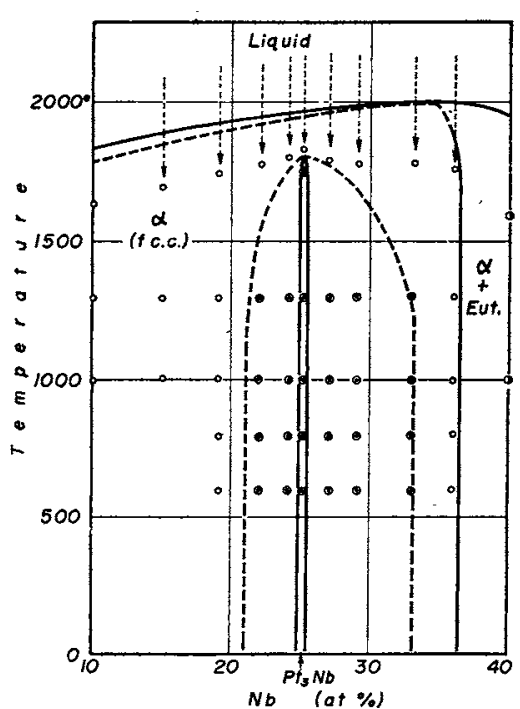

Fig. 3 Phase relationships in the region of formation of the super lattice, examined by powder $\mathrm{X}$-ray analysis.

程度となる。常温加工は $6 \% \mathrm{Nb}$ 安での合金に対して適用 することが出来るが $7 \% \mathrm{Nb}$ 以上の 合金に対しては高温加
とよく一致し ており $36 \%$ までは単相で ある.Photo. 1〜2に艺 の例を示す. $\alpha$ 相合金の硬 度は Nbの添 加量にほぼ比 例して硬くな つている。通 常焼鈍状態の PtではV.H. N 40 である 加 $6 \% \mathrm{Nb}$ 合 金ではV.H. N 200, $20 \%$ $\mathrm{Nb}$ 合金では V. H. N 480 对しては高温加 
エによらなけ机ばならない、さらに 10\%以上の試料では 望性加工を施すことが出来なかつた。

\section{2. $P t_{3} \mathrm{Nb}$ の规則格子変態について}

$25 \%$ 合金は $\mathrm{Pt}_{3} \mathrm{Nb}$ の化学組成酒相当し，この試料住融 液より急冷( 約 $1000^{\circ} / \mathrm{sec}$ ) すれ ばf.c.c.の結晶構造であるが， $1300^{\circ} 20 \mathrm{hr}$ の熟处理によつて Photo.3 亿示すよ5飞結晶丵 造が变化している.この新しい 相の結晶構造は現在では未決定 であるが，やや複雑な構造を持 つ規則格子と考光られる。これ らの問題を明らかたするために 22〜33\%の範围を2\%扣きに試 料を作り, $1300^{\circ} 20 \mathrm{hr}, 1000^{\circ}$

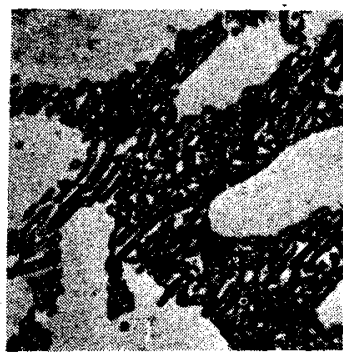

Photo. 640 at $\%$ alloy, as cast, Primary $\alpha+$ eutectic. $\quad(\times 1000)$
$100 \mathrm{hr}, 800^{\circ} 500 \mathrm{hr}$ 於よび $600^{\circ}$ で $1000 \mathrm{hr}$ の熱処理を行 つてX線により検討した。結果はFig.3 の如くである. 25 \%を中心とした試料では規則格子変態が認められたがこ の変熊速度は低い温度ではかなり緩馒であるたる変態前の f.c.c. 構造も残留して重複したデバイ写真を与兄る。また 鋳造状態では旁態がすでに部分的に進んでいて主とてて f.c.c. 構造であるが，少量の規則格子を含屯ようなデン゙イ 写真を与交る

こ狄らのとにより不規則二規則格子変態は融点直下の 䄪 $1800^{\circ}$ で起るものと孝えられ，その変態速度は高温度で は極めて早く進行するが，焼入れによつて阴止することが 出来る。また $1000^{\circ}$ 以下で変熊速度が避く $500 \sim 1000 \mathrm{hr}$ の長時間でもな秥完結しない。

\section{3. $\mathrm{PtNb}_{2}$ 相}

$\mathrm{PtNb}_{2}$ は Greenfieldら(1)炕よれば正方晶の結晶構造を

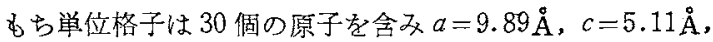
$c / a=0.52$ である.この相について検討するため $\mathrm{PtNb}_{2}$ を中心として $55 \%, 60 \%, 62 \%, 64 \%$ ，物よび 66\%，Nb の武 料を作り鋳造状態就よび $1000^{\circ}, 100 \mathrm{hr}$ の絖鈍を行つてX

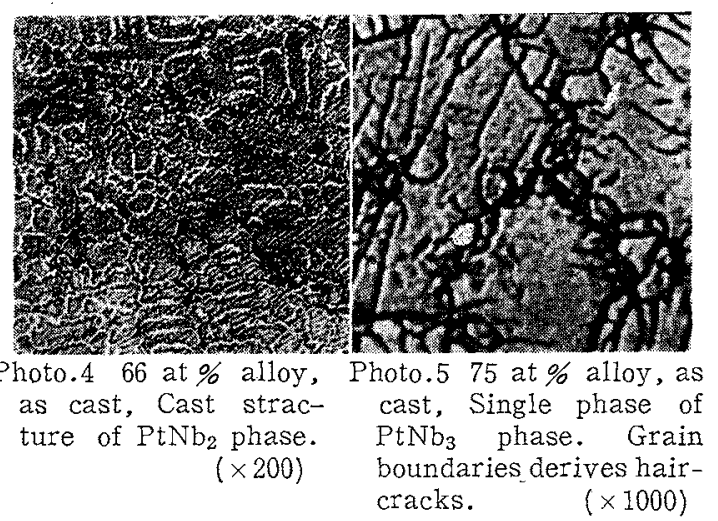

線分析之顕微鏡検查により検討した。

X線分析の結果はGreenfield らの結果之一致し，また $\mathrm{Nb}$ 含有量の变化による格子常数の変化は認められなかっ
た．顕徽鏡検沓の結果はPhoto.4のように铸造組織では 包晶反応の結果生じた過冷組織を示している.PtNb2 度はV.H.N.930で極めて脆い相で方る。

4. $\mathrm{PtNb}_{3}$ 相

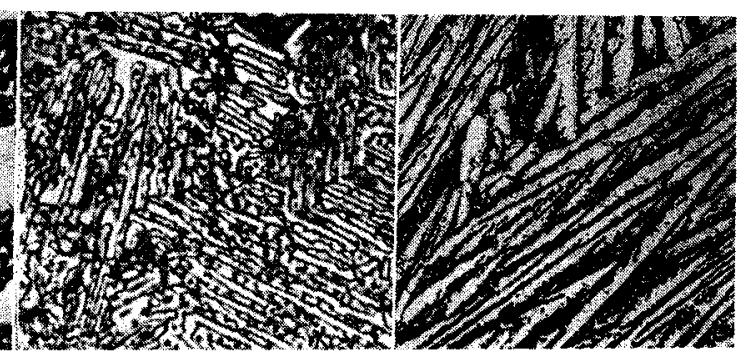

Photo.7 45 at $\%$ alloy, as Photo. 855 at $\%$ alloy, as cast, Eutectic of $\alpha$ and cast, Primary $\mathrm{PtNb}_{2}+$ $\mathrm{PtNb}_{2} \quad(\times 1000)$ eutectic. $(\times 200)$

$\mathrm{PtNb}_{3}$ の結晶構造は $\beta-\mathrm{W}$ 型立方晶で格子常数は $5.11 \AA$ (1) 乱よび $5.153 \pm 0.003 \AA$ (2) 亡報告されている.この実驗 では75〜80\% Nb の範再では $\mathrm{Nb}$ 含有量が增加すれば格子 常数は大となり $75 \%$ で $5.137 \mathrm{kX}, 80 \%$ では $5.156 \mathrm{kX}$ あつた。硬度はV.H.N $970 て ゙$ 極めて硬いが脆い相である。 Photo.5に示すように結晶粒界に微細なとビ割れが認め られる。この試料は再熔解のとさアーク熔解伴う急激な 加熱のた如に割れたり，甚たしい時には試料の大部分が飛

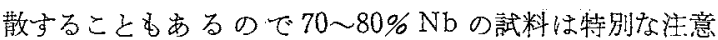
を払つて熔解を行らことが必要であつた。

\section{5. $\alpha$ 相と $\mathrm{PtNb}_{2}$ 間の共晶反応について}

Pt 側 $\alpha$ 相は $36 \% \mathrm{Nb}$ 委での領域を与めているが，この 固溶限を越えて $\mathrm{Nb}$ 含有量が堌加すればPhoto.6に示与 上らに $40 \% \mathrm{Nb}$ では初晶 $\alpha$ 之共晶の組織をもつている。 45\% Nbでは Photo.7 に示すように共晶組織でさらに Nb 含有量が多くなればPhoto. 8 に示すように初晶としてPt

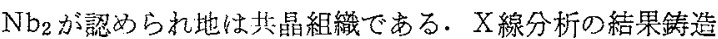
組織で住 $\alpha$ と $\mathrm{PNb}_{2}$ との混合図型が得られた。融点測定 の結果は $45 \% \mathrm{Nb}$ に和いて約 $1700^{\circ}$ の極小㑷を示した。こ れらの結果炕り Pt-Nb系には $45 \%, 1700^{\circ}$ で次の其晶反 応があ。

$$
\mathrm{Liq} . \rightleftharpoons \alpha+\mathrm{PtNb}_{2}
$$

なお $50 \% \mathrm{Nb}$ の組成では $1000^{\circ} 100 \mathrm{hr}$ の熱処理によつ て $\alpha$ 执よび $\mathrm{PtNb}_{2}$ のいず狄も属していないデバイ輸が 微弱であるが重複して認められる。これについては今後の 検討が必要で㐫るが，PtとNbの比が 1 対1の組成で固体 反応で生ずるPtNbの金属間化合物の存在が甬想される。

6. $\mathrm{PtNb}_{2}$ と $\mathrm{PtNb}_{3}$ 間の包晶反応について

$\mathrm{PtNb}_{2}$ と $\mathrm{PND}_{3}$ との關の試料はX線分析の結果ではそ れぞれの混合組織で，融点は $\mathrm{PtNb}_{2}$ では約 $2000^{\circ}$ である

(1) P.Greenfield, P.A.Beck: J.Metals, 8(1956), 268.

(2) S.Geller, B.T.Mathias, and R.Goldstein : J. Amer. Chem. Soc., $77(1955), 210$. 
が， $\mathrm{PtNb}_{2}$ の側に移るに従つて低くなり $\mathrm{PtNt_{2 }}$ では $1930^{\circ}$ でこの点を越点て $45 \%$ の其晶点 $\left(1700^{\circ}\right)$ まで連続的に低く なつている. $66 \% \mathrm{Nb}$ の鋳造組織を拡大して観察すると Photo.9に示したよ5にこの条件では過冷の包晶組織を

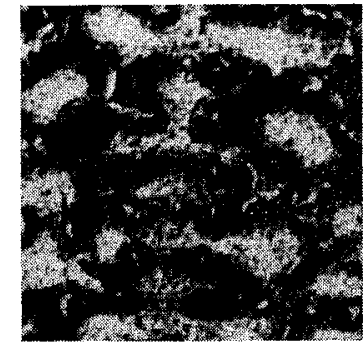

Photo. 966 at $\%$ alloy, as cast, Super cooled stracture of $\mathrm{PtNb}_{2} .(\times 1000)$

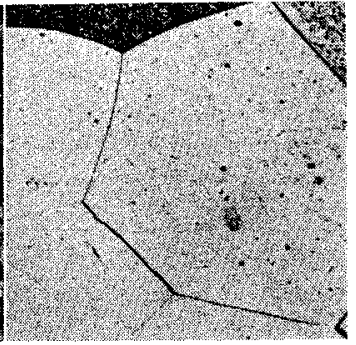

Photo.10 99 at \% alloy, as cast, Single phase of niobium rich solid solution. $\quad(\times 200)$

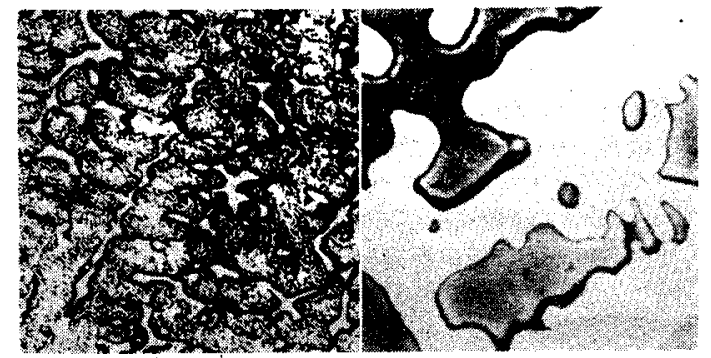

Photo.11 97 at $\%$ alloy, as cast, Primary Nb solid solution and $\mathrm{PtNb}_{3}$. $(\times 200)$

Photo. 1285 at $\%$ alloy, as cast, Plimary $\mathrm{Nb}$ solid solution and $\mathrm{PtNb}_{3}$. $\quad(\times 1000)$

示している.これらのことより Pt-Nb 系には66\%,1900 で次の包晶反応がある.

$$
\mathrm{Liq} .+\mathrm{PtNb}_{3} \rightleftharpoons \mathrm{PtNb}_{2}
$$

\section{7. $\mathrm{Nb} \mathrm{PtNb}_{3}$ 間の包晶反応について}

$\mathrm{Nb}$ と $\mathrm{PtNb}_{3}$ との間の組成の試料はX線分析の結果は鉿 造状態と $1000^{\circ}$ の熱処理の状態で変化はなく、いずれす $\mathrm{Pt}$ $\mathrm{Nb}_{3}$ の立方晶と $\mathrm{Nb}$ の b.c.c.との混会であつて,それぞれ の濃度志組成に徒つて順次变化している。骶点はNbの $2430^{\circ}$ よりPtの含有量に従いはぼ直線的低くなつて $\mathrm{PtNb}_{3}$ の $2000^{\circ}$ に続いている.

影微鏡組織はNbに対しPt1\%あではPhoto.10に示 すように単相であるがこれ以上 Ptが多くなれば $3 \%$ Pt ではPhoto.11に示すように $\mathrm{PtNb}_{3}$ 相が認められ, 5\% Pt
ではX線分析でも明らかと $\mathrm{Nb}$ 基の中に $\mathrm{PtNb}_{3}$ 相が識別 出来了。

さらにPt 含有量が多くなれば初晶の Nb 相の量が少く なつて例えば $85 \%$ NbではPhoto.12 に示すような包晶組 織者示している. 従つて PtNb 3 は 75\%,2000\%に抬いて次 の包晶反応により生ずるすのである。

$\mathrm{Iiq} \cdot+\mathrm{Nb} \rightleftharpoons \mathrm{PtNb}_{3}$

\section{IV. 結言}

Pt-Nb 2 元系はFig.4の上5に与光られる.この系に存 在する相及び反応は次の如くである。

(1) Pt 側 $\alpha$ 相は 36\% での Nb を固溶し，その格子常 数はPtの3.916 kXより $3.956 \mathrm{kX}$ まで大となる・蛧点は $\mathrm{Nb}$ の添玑により高くなり $36 \%$ で $2000^{\circ}$ の極大を示す。

(2) $\mathrm{Pt}_{3} \mathrm{Nb}$ の組成では融点の直下で規則格子を作りその

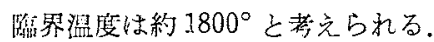

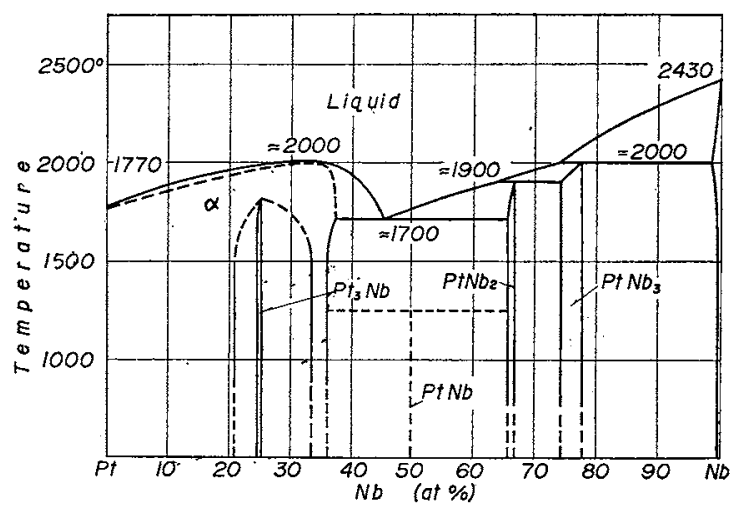

Fig. 1. Equilibrium diagram of platinum-niobium system.

(3) $\mathrm{PtNb}_{2}$ 相心正方晶の構造老ち $a=9.89 \mathrm{kX}, c=$ $5.11 \mathrm{kX}, c / a=0.52$ である.

(4) $\mathrm{PtNb}_{3}$ 相は $\beta-\mathrm{W}$ 型の立方晶で $\mathrm{Nb}$ の含有量が多く なれば $a=5.137 \mathrm{kX}$ より $5.156 \mathrm{kX}$ まで大となる・この相

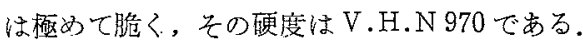

(5) Nbは高温で約 $1 \%$ Ptを固溶寸る。

(6) $\mathrm{Pt}(\alpha)$ とtNb 2 の間には次の包晶反心がある.

$\mathrm{Liq} . \rightleftharpoons \alpha+\mathrm{PtNb}_{2}, 45 \%, 1700^{\circ}$

(7) $\mathrm{PtNb}_{2}$ と $\mathrm{PtNb}_{3}$ との間火は次の包晶反広がある。

Liq. $+\mathrm{PtNb}_{3} \rightleftharpoons \mathrm{PtNb}_{2}, 66 \%, 1900^{\circ}$

(8) $\mathrm{Nb}$ と $\mathrm{PtNb}_{3}$ との間火は次の包晶反忘がある.

Liq. $+\mathrm{Nb}_{2} \rightleftharpoons \mathrm{PtNb}_{3}, 75 \%, 2000^{\circ}$ 